\title{
Mycoparasitic nature of Egyptian Trichoderma isolates and their impact on suppression Fusarium wilt of tomato
}

\author{
A. M. Nofal', Mohamed Abd El-Rahman', T. M. Abdelghany ${ }^{2^{*}}$ (1) and Mahmoud Abd El-Mongy ${ }^{3}$
}

\begin{abstract}
Background: Plant disease administration is difficult due to the soil-borne nature of the phytopathogens. Biological control of plant disease is a safe mode to avoid the problems related to fungal diseases that affect crops productivity.

Results: Twenty-three Trichoderma isolates were isolated from soil, surrounding healthy tomato roots from different regions in the Egyptian Governorate of Menoufia. Using a dual culture method to test the efficiency of Trichoderma isolates, the most effective isolate identified as Trichoderma atrovirde with percentage inhibition against Fusarium oxysporum f. sp. lycopersici (92.11\%) and scanning electron microscope examination documented the mycoparasitic nature of T. atrovirde to F. oxysporum. Treatments with 10\% filtrate T. atrovirde improved the growth aspects of tomato plants than the control plants or infected only, as well as the increase in phenol content $\left(15.09 \mathrm{ug} \cdot \mathrm{g}^{-1} \mathrm{dry}\right.$ weight) and decreased disease incidence percentage (8\%) than the plants infected only (60\%).

Conclusions: This study clearly demonstrated that T. atrovirde had a significant inhibition against F. oxysporum. Greenhouse assays displayed the protective role of $T$. atrovirde inoculation directly against pathogen or indirectly related to the defense mechanism in the plant. So, this study recommends using T. atrovirde for biological control of wilt disease in tomato plants.
\end{abstract}

Keywords: Fusarium oxysporum, Trichoderma spp., Biological control, Mycoparasitism, Tomato

\section{Background}

Tomato (Solanum lycopersicum) is a very economic vegetable crop cultivated in various regions of the world. Fusarium oxysporum is the causative agent of Fusarium wilt which has proved to be the most destructive disease affecting a wide variety of plants including weeds and commercially domesticated plants and crops. The disease results in a range of symptoms ranging from yellowing of the leaves, browning of the vascular tissue, sluggish growth, and even death of plants (Renu 2018). F. oxysporum is essential and a variety of pathogenic plant fungus (Anjul et al. 2017). Fusarium oxysporum $\mathrm{f}$.

\footnotetext{
*Correspondence: tabdelghany.201@azhar.edu.eg; tabdelghany@yahoo.com ${ }^{2}$ Botany and Microbiology Department, Faculty of Science, Al-Azhar University, Cairo, Egypt

Full list of author information is available at the end of the article
}

sp. lycopersici was reported as a causative agent of tomato wilt in Egypt (Abo-Elyousr and Mohamed 2009). Wilt is one of the world's most economically important diseases (Fang et al. 2020). The toxicity of chemical fungicides for the soil and polluted environment was confirmed previously; therefore, biological control of fungal disease is considered a practicable alternative and safe friendly manner (Saad et al. 2019).

Biological control is an important manner of control the disease for phytopathogenic fungi, particularly for soil-borne pathogens. In recent years, the most abused biocontrol agents are the species of Trichoderma (Shrinkhala et al. 2019). Soil-borne plant pathogens controlled by using Trichoderma have been reported for biological control (Mohamed et al. 2020). With the application of various species of Trichoderma, remarkable decreases in

\section{Springer Open}

() The Author(s). 2021 Open Access This article is licensed under a Creative Commons Attribution 4.0 International License, which permits use, sharing, adaptation, distribution and reproduction in any medium or format, as long as you give appropriate credit to the original author(s) and the source, provide a link to the Creative Commons licence, and indicate if changes were made. The images or other third party material in this article are included in the article's Creative Commons licence, unless indicated otherwise in a credit line to the material. If material is not included in the article's Creative Commons licence and your intended use is not permitted by statutory regulation or exceeds the permitted use, you will need to obtain permission directly from the copyright holder. To view a copy of this licence, visit http://creativecommons.org/licenses/by/4.0/. 
Fusarium wilted in several crops were recorded (Ramezani 2009).

The goal of the present work was to evaluate the efficiency of 23 Trichoderma spp. isolates in bio-control of F. oxysporum under in vitro and greenhouse conditions.

\section{Methods \\ In vitro experiments \\ Isolation, purification, and identification of Fusarium \\ oxysporum}

Diseased tomato plants were collected from different regions of the Governorate of Elmenofya (Shebin El Kom, Kafer Dawood, and Bader), Egypt, showing various degrees of wilt symptoms. Infected roots were washed thoroughly with flowing tap water and cut into small pieces before plunging into sodium hypochlorite $(0.5 \%$ chlorine) for $1 \mathrm{~min}$. The surfaces were washed by distilled water, dried between 2 sterilized filter sheets, placed directly in Petri dishes on potato dextrose agar (PDA) medium, and incubated at $28^{\circ} \mathrm{C}$ for 3 days. Analysis was carried out when the fungal growth originated from the incubated materials. All the isolated fungi were extracted using single spore, or hyphal tip techniques were suggested by Dhingra and Sinclair (1985). The fungi were identified according to their morphological characteristics according to Booth (1985) and confirmed in Mycology center (MC), Assuit University, Egypt. The stock of isolates was stored on PDA slants and kept at $5-10^{\circ} \mathrm{C}$ in a refrigerator for further study.

\section{Pathogenicity test of $F$. oxysporum Pot and soil sterilization}

Earthenware pots $(20 \mathrm{~cm}$ in diameter) were sterilized by plunging them into a $5 \%$ formalin solution for $15 \mathrm{~min}$ and covered overnight with plastic sheets, then left to dry. Soil sterilization was carried out by autoclaving for $1 \mathrm{~h}$ at $121^{\circ} \mathrm{C}$.

\section{Nursery preparation}

Susceptible marmand tomato cultivar obtained from the Research Institute of Horticulture, Agricultural Research Center (ARC), Giza, Egypt. Tomato seeds were sterilized by $1 \%$ sodium hypochlorite on the surface for $1 \mathrm{~min}$, then washed in several changes of sterilized water, and left to dry. Sterilized seeds were sown on the surface in sterilized soil and irrigated with water for 30 days.

\section{Inoculum preparation and soil infestation}

Bottles containing the medium sand-barley were autoclaved and then the isolated fungus was inoculated after 2 weeks of incubation at $28^{\circ} \mathrm{C}$. The fungus was thoroughly mixed with sterilized soil at a rate of $1 \mathrm{gm}$ inoculum $/ 1 \mathrm{~kg}$ soil. Inoculated pots were watered regularly, 7 days before planting. The pots used as control were packed by a soil free-sand barley medium fungus (Shehata 2001).

\section{Transferring of transplants and cultivation}

Transplants were transferred to infested soil and planted under sterilized conditions. Five transplants were planted in sterilized un-infested soil. The wilting \% after 30 days of transplant cultivation was recorded as follows:

$$
\text { Wilting } \%=\frac{\text { Number of wilting plants }}{\text { Total number of plants }} \times 100
$$

\section{Isolation of Trichoderma spp. from rhizospheric region} Rhizospheric soils were collected from different regions of Egypt. Trichoderma spp. were isolated from the rhizosphere soil samples by dilution plate technique, using PDA and Trichoderma selective medium (TSM). Trichoderma spp. were purified, using the hyphal tip technique (Tuite 1996). The isolated species (T1, T2, T3...T23) were identified dependent upon growth, mycelium structure, conidiophores, phialides, and conidia on colony characters.

\section{Dual culture experiment}

Antagonistic efficacy of Trichoderma spp. isolates was tested against the isolated pathogenic fungus by dual culture experiment (Dennis and Webster 1971). Disc of growth agar medium of Trichoderma was placed against component $F$. oxysporum and the 6-day incubation at $28 \pm 2^{\circ} \mathrm{C}$ monoculture plates served as controls of both, 7 days after incubated radial growth, measured for $F$. oxysporum and Trichoderma spp. The colony diameter of test fungus was observed and compared with control on a dual culture plate. The percentage of the inhibition of radial growth (\% RGI) was determined using formula:

$$
\mathrm{RGI} \%=\frac{\mathrm{C}-\mathrm{T}}{\mathrm{C}} \times 100
$$

where $C$ is the growth of test pathogen with the absence of antagonist and $\mathrm{T}$ is the growth of test pathogen with of antagonist (Pandey and Vishwakarma 1998).

\section{Identification of active Trichoderma isolates}

The potent inhibitor of Trichoderma isolates against the tested phytopathogenic fungus was selected for identification up to colony character, growth, mycelium structure, conidiophores, phialides, and conidia (Kubicek and Harman 2002). Confirmed identification was done at MC.

\section{Preparation of scanning electron microscopy (SEM)}

Interaction among hyphae of pathogen $F$. oxysporum and bio-control agent $T$. atroviride was examined using 


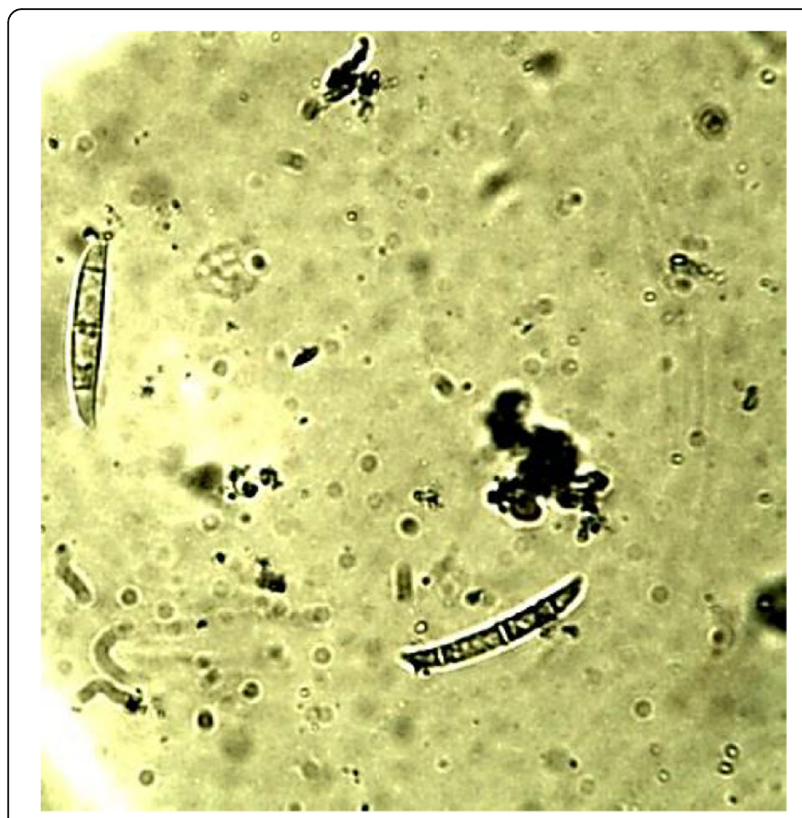

Fig. 1 Conidia of F. oxysporum ( $\times 400)$ light microscope

the scanner electron microscope (SEM). To obtain hyphae touch sites, PDA plate was inoculated with a mycelial disk $(5 \mathrm{~mm})$ cut from the front edge of the 2 at a constant distance from the edge of the Petri plate. From colonies $F$. oxysporum and $T$. atroviride, the 2 fungi grow up to each other, their hyphae mixed. After 4 days of incubation, the plate cultures were examined under a light microscope to check the early stage of touch. The contact sites were labeled, and blocks of $1 \mathrm{~cm}$ agar were removed for SEM preparation, were fixed with osmium oxide, and then were dehydrated using a serial dilution
Table 1 Pathogenicity test for different isolates of F. oxysporum

\begin{tabular}{lllll}
\hline Isolate & Location & Total No. of plants & ${ }^{\text {a Wilting }}$ & DI $^{\mathbf{a}}$ (\%) \\
\hline F1 & Shebin El kom & 25 & 15 & 60 \\
F2 & Kafr dawood & 25 & 12 & 48 \\
F3 & Bader & 25 & 11 & 44
\end{tabular}

${ }^{a}$ Each value represents the mean values of 3 replicates

of the ethyl alcohol finally acetone. A critical point drier (EMS 850) was then used to dry the processed samples, coated with gold using a sputter coater (EMS 550), and then SEM (JEOL100CX-ASID-4D) was used to examine the samples at the Regional Center for Mycology and Biotechnology Center, Egypt.

\section{In vivo experiments}

Effect of T. atroviride on tomato plants infected with $F$. oxysporum

Planting, growth conditions, and treatments Susceptible tomato seeds (marmand) were sterilized on the surface for $1-3 \mathrm{~min}$ in $0.01 \%$ mercury chloride and washed with sterilized distilled water, then planted for 30 days in sterilized plastic pots containing sterilized soil before transplants were developed. The inoculum was prepared by introducing five discs of a 7-day-old culture of $F$. oxysporum grown on PDA medium into 500-ml size bottles containing sand-cornmeal medium (SCM), then incubated at $28^{\circ} \mathrm{C}$ for 14 days (Shehata 2001). The inoculum of $F$. oxysporum was added to sterilized pots (12 $\mathrm{cm}$ diameter $\times 20 \mathrm{~cm}$ height), containing $2.5 \mathrm{~kg}$ sterilized soil at the rate of $10 \mathrm{~g}$ inoculum/one $\mathrm{kg}$ soil, then watered whenever needed for 7 days. Healthy root systems of tomato transplants were soaked for 1-2 h
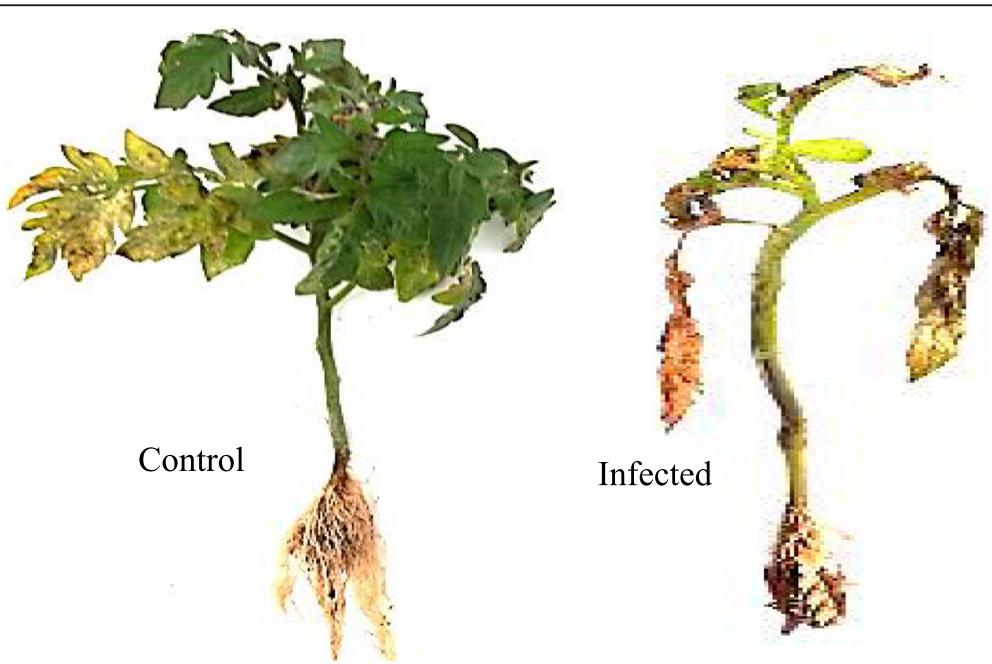

Fig. 2 Healthy tomato plants (control) and infected tomato plants (showed wilting symptoms) 


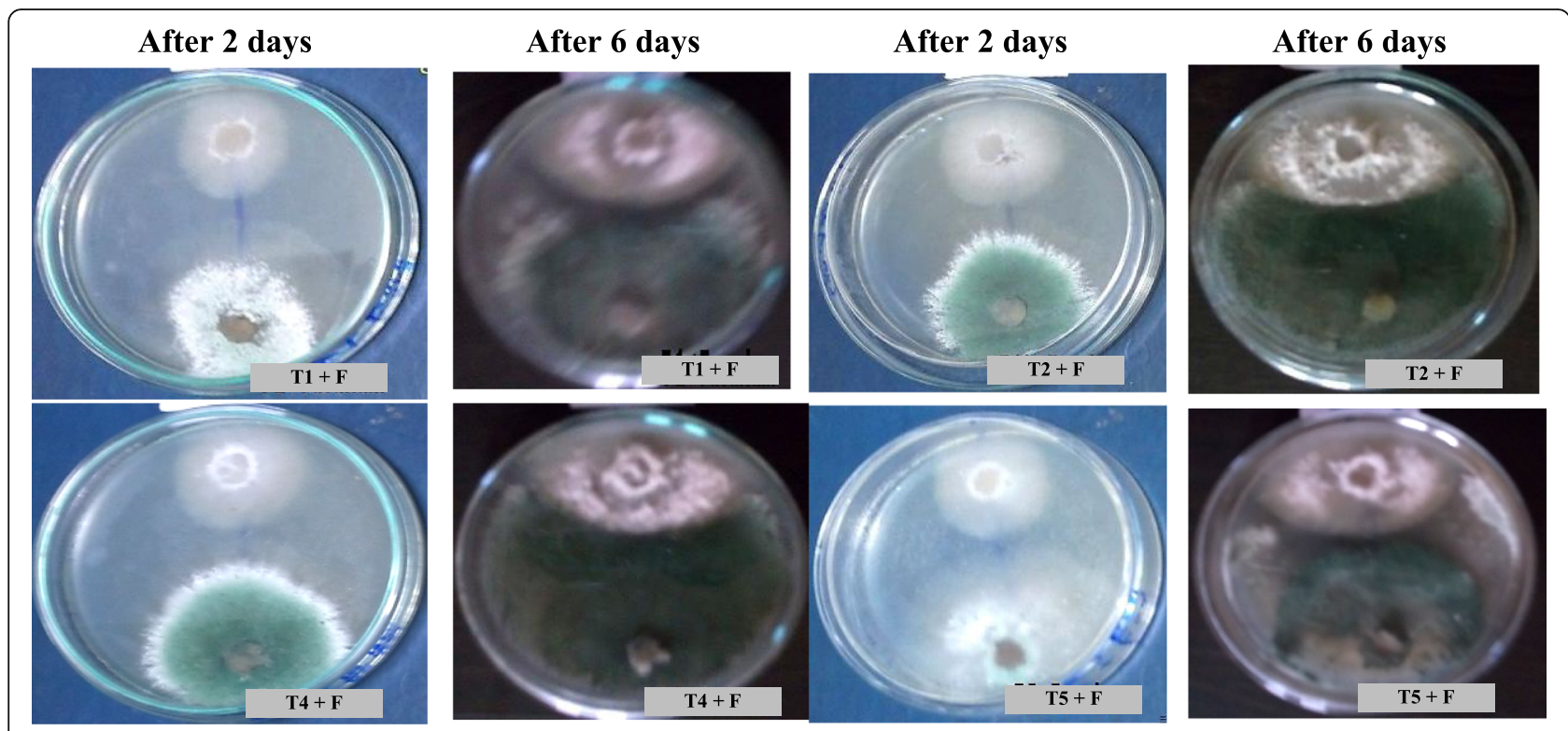

Fig. 3 Effect of Trichoderma antagonists on the mycelial growth of F. oxysporum (F) under in vitro conditions

in the $10 \%$ suspension of $T$. atroviride. Control roots were immersed in water only. Five pots, each containing 5 transplants, were used for each treatment. The fungicide Rizolex-T (Tolclofosm methyl+ Thiram) from Sumitomo Chemical Company Japan was used through this experiment for comparison at the recommended dosage (3 gm/l water) according to the Ministry of Agriculture, Egypt. The experimental design can be summarized as follows: $\mathrm{C}=$ (control), $\mathrm{P}=$ (pathogen), ( $F$. oxysporum), $\mathrm{P}+\mathrm{F}$ (pathogen + fungicide), and $\mathrm{P}+\mathrm{T}$ (pathogen + T.atroviride). Data of this experiment were recorded 30 days after transferring. For each treatment, 3 plants were harvested and carefully washed by flowing water to dissolve debris from the soil. The following parameters were measured for the tomato plants: shoot length $(\mathrm{cm})$, root length $(\mathrm{cm})$, number of leaves, fresh and dry weight of shoot (gm), fresh and dry weight of root (gm), number of wilting plants, total number of plants, root surface area, and estimation of total phenol (ug. $\mathrm{g}^{-1}$ dry weight) and was performed in accordance with the method described by Folin Ciocalteau reagent (Malik and Singh 1980).

The disease incidence (DI) was measured as follows:

$$
\mathrm{DI} \%=\frac{\text { Number of wilting plants }}{\text { Total number of plants }} \times 100
$$

\section{Statistical analysis}

All values were the sum of the triple determinations. Data was statistically analyzed using the SPSS (1999)
Table 2 Antagonists effect of Trichoderma isolates on the growth of F. oxysporum under in vitro conditions

\begin{tabular}{|c|c|c|}
\hline \multirow{2}{*}{$\begin{array}{l}\text { Trichoderma } \\
\text { isolates }\end{array}$} & \multicolumn{2}{|l|}{ F. oxysporum } \\
\hline & ${ }^{\mathrm{a}}$ Growth $(\mathrm{mm})$ & ${ }^{\mathrm{a}}$ Growth inhibition (\%) \\
\hline Control & $85.0 \mathrm{a}$ & 0.00 \\
\hline T1 & $38.3 b c$ & 54.94 \\
\hline $\mathrm{T} 2$ & $6.7 \mathrm{k}$ & 92.11 \\
\hline T3 & 35.7 defc & 58.00 \\
\hline T4 & 33.7efg & 60.35 \\
\hline T5 & $39.7 b$ & 53.29 \\
\hline T6 & $37.3 \mathrm{dbc}$ & 56.11 \\
\hline $\mathrm{T} 7$ & 35.3defc & 58.47 \\
\hline T8 & $27.3 \mathrm{kj}$ & 67.88 \\
\hline T9 & 35.5 defc & 58.23 \\
\hline T10 & $40.3 b$ & 52.58 \\
\hline T11 & 30.7ihg & 63.88 \\
\hline T12 & 27.7ikj & 67.41 \\
\hline T13 & 33.3efg & 60.82 \\
\hline T14 & 30.0ihj & 64.70 \\
\hline T15 & 35def & 58.82 \\
\hline T16 & 32.7hfg & 61.52 \\
\hline T17 & 30.0ihj & 64.70 \\
\hline T18 & 34.0ef & 60.00 \\
\hline T19 & $36.3 \mathrm{dec}$ & 57.29 \\
\hline $\mathrm{T} 20$ & 30.7ihg & 63.88 \\
\hline T21 & 28.3ikj & 66.70 \\
\hline T22 & 32.7hfg & 61.52 \\
\hline T23 & $37.3 \mathrm{dbc}$ & 56.11 \\
\hline L. S. D. & 3.03 & \\
\hline
\end{tabular}

${ }^{a}$ Each value represents the mean values of 3 replicates. Means having the same alphabetical letter in column, within a comparable group of means, do not significantly differ, using Duncan's multiple range test procedure at $p=0.05$ level of significance 


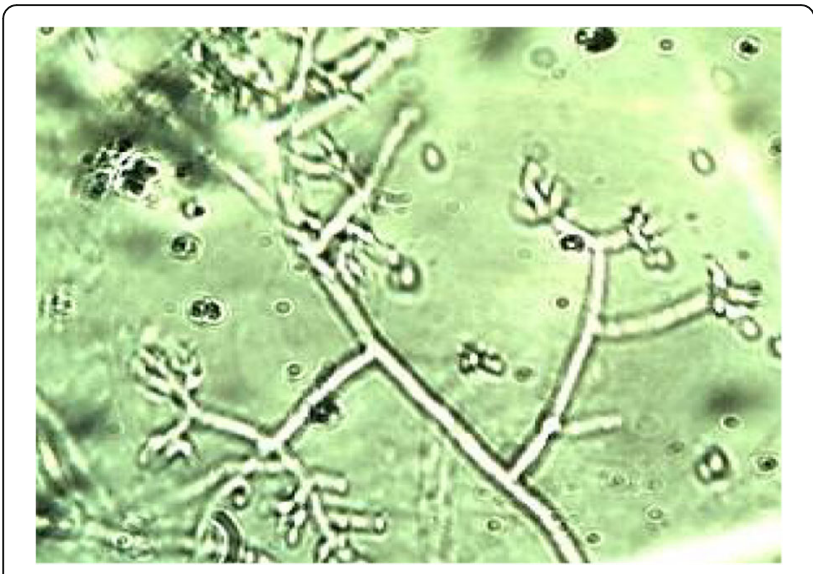

Fig. 4 Trichoderma atroviride Karsten $(\times 400)$

one-way variance analysis (ANOVA). The small difference was shortened as LSD and measured at $P \leq 0.05$.

\section{Results}

In vitro experiments

Phyto-pathological studies

Isolation, purification, and diagnosis of the causative agent of wilt disease The causative agent of wilt disease was isolated from diseased tomato roots collected from various regions of the governorate of Elmenofya (Shebin El Kom, Kafr Dawood, and Bader) and described according to the morphological and microscopic characteristics (mycelial production and spore formation). The isolate was identified as F. oxysporum (Fig. 1) and confirmed at MC as F. oxysporum 9704 AUMC.

Pathogenicity test of $\boldsymbol{F}$. oxysporum All the isolates of F. oxysporum obtained from the infected tomato roots were examined for their pathogenicity on healthy
Table 3 Effect of T. atroviride on DI of tomato plants infected by F. oxysporum

\begin{tabular}{llll}
\hline Treatment & Total No. of plants & ${ }^{\text {a Wilting }}$ & DI $^{\text {a }}$ (\%) \\
\hline Control & 25 & 0 & Od \\
F. oxysporum & 25 & 15 & $60 \mathrm{a}$ \\
F. oxysporum + Rhizolex & 25 & 2 & $8 \mathrm{~b}$ \\
F. oxysporum + T. atroviride & 25 & 2 & $8 \mathrm{~b}$ \\
L. S. D. & & & 2.71 \\
\hline
\end{tabular}

${ }^{a}$ Each value represents the mean values of 3 replicates. Means having the same alphabetical letter in column, within a comparable group of means, do not significantly differ, using Duncan's multiple range test procedure at $p=$ 0.05 level of significance

susceptible tomato roots marmand to determine the most aggressive one. Control plants showed no symptoms, while the inoculated plants indicated that all isolates were pathogenic, resulting in typical wilt disease symptoms (Fig. 2) from isolates, Shebin El Kom (F1) isolate $F$. oxysporum reported the highest DI (60\%) (Table $1)$. Therefore, this isolate was considered the most offensive and used for further research.

Isolation of Trichoderma isolates Obtained results reflected the growth of 23 isolates of Trichoderma from all collected rhizospheric soils. These soil samples from different regions of Egypt were considered as a source of Trichoderma isolates; therefore, the Trichoderma isolates were numbered (T1, T2, T3, .... T23) and applied for further studies.

Screening for antagonistic potential of Trichoderma isolates against $F$. oxysporum (dual culture experiments) On the PDA medium, the effectiveness of local Trichoderma isolates was determined to inhibit $F$. oxysporum myclial development in dual culture, and the inhibitory effect was remarkably at 6 days of incubation
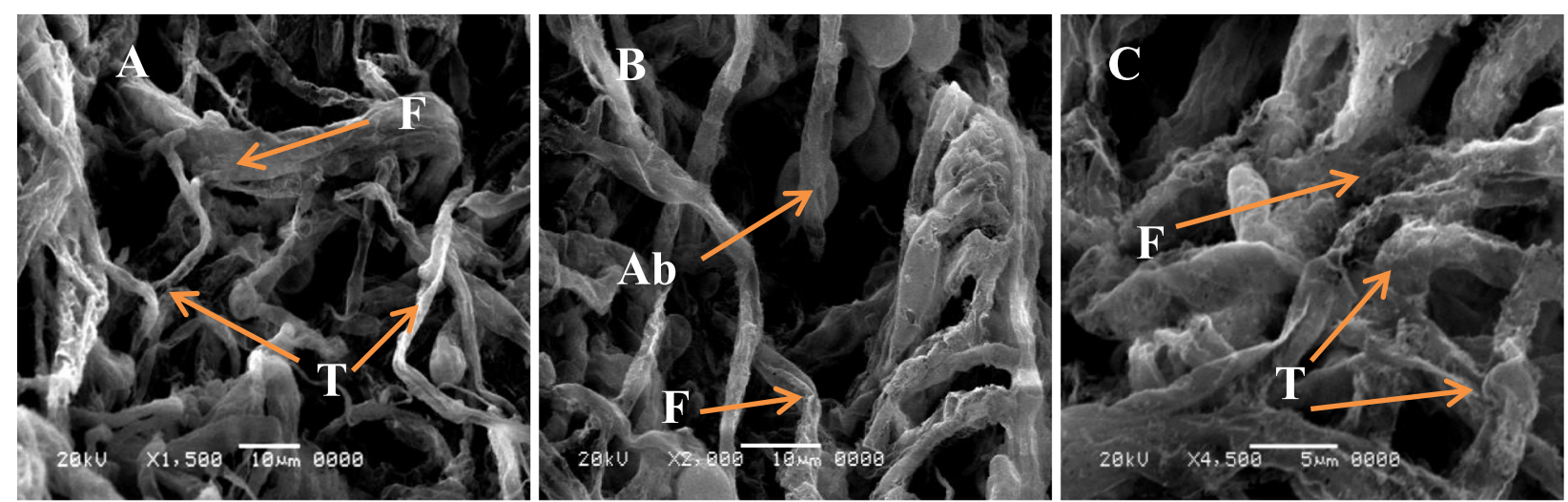

Fig. 5 Scanning electron microscopy observations of the mycoparasistic nature of T. atroviride on F. oxysporum. A Growing of Trichoderma hyphae (T) parallel to Fusarium hyphae (F) \& coling of (T) around (F); B Sticking of of Trichoderma hyphae (T) with Fusarium hyphae (F) and formed of appressoria like structures, "Ab"; C Finally the Fusarium wall lysed 
Table 4 Effect of T. atroviride on growth parameters of tomato plant infected by F. oxysporum

\begin{tabular}{|c|c|c|c|c|c|c|c|c|}
\hline \multirow[t]{2}{*}{ Treatment } & \multicolumn{8}{|c|}{${ }^{\mathrm{a} G r o w t h}$ parameters } \\
\hline & $\begin{array}{l}\text { RL } \\
(\mathrm{cm})\end{array}$ & $\begin{array}{l}\text { RFW } \\
\text { (gm) }\end{array}$ & $\begin{array}{l}\text { RDW } \\
\text { (gm) }\end{array}$ & $\begin{array}{l}\text { SL } \\
\text { (cm) }\end{array}$ & $\begin{array}{l}\text { SFW } \\
\text { (gm) }\end{array}$ & $\begin{array}{l}\text { SDW } \\
\text { (gm) }\end{array}$ & Leaves NO & $\begin{array}{l}\text { RSA } \\
\text { (cm) }\end{array}$ \\
\hline Control & $14 \mathrm{~b}$ & $3.87 \mathrm{ab}$ & $1.61 \mathrm{~b}$ & $18 a b$ & $12.83 \mathrm{ab}$ & $6.00 \mathrm{ab}$ & $9 \mathrm{ab}$ & $13.45 c$ \\
\hline F. oxysporum & $8 d$ & $0.69 \mathrm{c}$ & $0.44 c$ & $11 \mathrm{c}$ & $2.92 \mathrm{~d}$ & $1.88 \mathrm{C}$ & $7 \mathrm{~b}$ & $16.55 \mathrm{ab}$ \\
\hline F. oxysporum + Rhizolex & $13 c$ & $2.49 \mathrm{~b}$ & $1.10 \mathrm{~b}$ & $16 b$ & $9.81 \mathrm{C}$ & $4.60 \mathrm{~b}$ & $7 \mathrm{~b}$ & $15.67 \mathrm{abc}$ \\
\hline F. oxysporum + T. atroviride & $15 \mathrm{~b}$ & $3.29 \mathrm{~b}$ & $1.86 \mathrm{~b}$ & $18 b$ & $11.79 \mathrm{bc}$ & $6.10 \mathrm{ab}$ & $8 a b$ & $15.09 \mathrm{cb}$ \\
\hline L. S. D. & 3.27 & 1.45 & 0.84 & 3.50 & 2.74 & 2.33 & 2.71 & 3.15 \\
\hline
\end{tabular}

${ }^{\mathrm{a}}$ Each value represents the mean values of 3 replicates. Means having an alphabetical letter in column, within a comparable group of means, do not significantly differ, using Duncan's multiple range test procedure at $\mathrm{p}=0.05$ level of significance.

$R L$ root length, $R F W$ root fresh weight, $R D W$ root dry weight, SL shoot length, SFW shoot fresh weight, SDW shoot dry weight, $R S A$ root surface area

(Fig. 3). F. oxysporum radial development was substantially inhibited by Trichoderma isolates of different grades (Table 2 and Fig. 3). Trichoderma isolates were able to inhibit the mycelial growth of $F$. oxysporum by percentage inhibition (52.58-92.11\%). The highest inhibition $(92.11 \%)$ was recorded with isolate $\mathrm{T} 2$, followed by T8 (67.88\%) and T12 (67.41\%), while the lowest inhibition $(52.58 \%)$ was with isolate T10. Therefore, the isolate T2, caused the highest antagonistic effect against tested phytopathogenic fungus, was selected for identification of its species level (Fig. 4). The identification was confirmed by MC (AUMC No.10639).

Scanning electron microscopy observations of the mycoparasistic nature of $T$. atroviride on $F$. oxysporum The mycoparasistic nature and events of $T$. atroviride on F. oxysporum as dual culture was examined by SEM (Fig. 5a-c). T. atroviride hyphae grew alongside hyphae of $F$. oxysporum, followed by quick and excessive coiling (plate a), and the formation on the surface of appressor-like structures on the surface of $F$. oxysporum hyphae (plate b). Then, F. oxysporum eventually lysis was observed (plate c).
In vivo effect of $T$. atroviride on tomato plants infected with F. oxysporum

Disease incidence

Obtained data represented in Table 3 showed that the DI was very high $(60 \%)$ in tomato plants infected with $F$. oxysporum than the control plants. While treatment with T. atroviride decreased DI to $8 \%$, the occurrence of the DI was substantially reduced by treating infected tomato plants, using $T$. atroviride alone or the Rhizolex fungicide.

\section{Growth parameters}

F. oxysporum infection of tomato plants significantly decreased all growth parameters (root length $(8 \mathrm{~cm})$, root fresh weight (0.69), root dry weight $(0.44 \mathrm{gm})$, shoot length $(11 \mathrm{~cm})$, and shoot fresh weight $(2.92 \mathrm{gm})$, while treatment with $T$. atroviride significantly enhanced the development of these parameters than the control plants (Table 4 and Fig. 6). The results showed that the plant infected only with $F$. oxysporum had a very low root surface area $(0.5 \mathrm{~cm})$ as compared with the control $(3 \mathrm{~cm})$, while sharply increment root surface area $(5 \mathrm{~cm})$ was observed in the infected plant, which treated with $T$. atroviride.
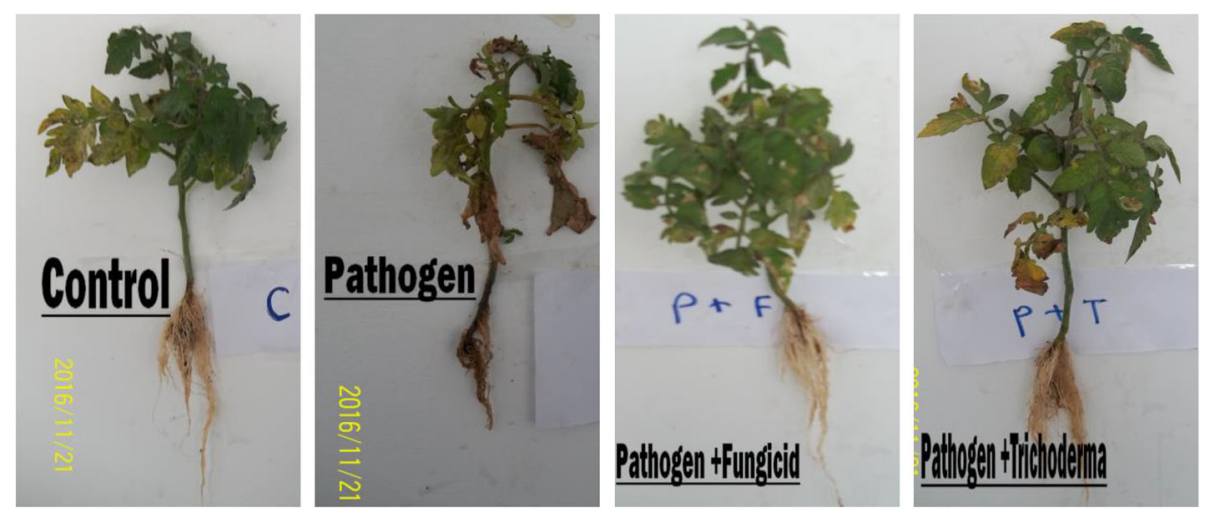

Fig. 6 Effect of T. atroviride on growth parameters of tomato plant infected with F. oxysporum 


\section{Discussion}

Fungal diseases are the major problems associated with plant development. Biological control is a safe mode to avoid lethal chemical fungicides inhibiting pathogens. In dual in vitro research, antagonistic ability of Trichoderma isolates showed inhibitory effect on F. oxysporum growth, the causal pathogen of tomato wilt disease, ranging from 52.58 to $92.11 \%$. The present study showed that $T$. atroviride was more successful in inhibition of $F$. oxysporum growth in vitro (Sallam et al. 2019). Dual culture approach was applied previously to determine the potential of $T$. harzianum to prevent the growth of $F$. oxysporum (Nwankiti and Gwa 2018). The antagonistic mechanisms of Trichoderma spp. against phytopathogenic fungi were described in numerous studies, for example, Shrinkhala et al. (2019) mentioned that Trichoderma spp. grew much faster leading to limit nutrients and space and therefore suppressed $F$. oxysporum which was responsible for the tomato wilting. SEM study on the antagonism between $T$. atroviride and $F$. oxysporum reported $T$. atroviride as mycoparasitic on F. oxysporum. Antagonism and increment of defensive mechanisms of plants are known to be mediated by a multiple of compounds produced by biocontrol agents, such as enzymes, toxic molecules, and volatile metabolites. The hydrolysis of the phytopathogenic fungi cell wall may take place by these enzymes. Trichoderma has been antagonized by antibiotics production against $F$. oxysporum and by mycoparasitism (El-Sobky et al. 2019).

Obtained results showed also that $T$. atroviride significantly reduced the DI of wilting on tomatoes with a reduction in disease ranging from 60 to $8 \%$ over time. Wilting in some leguminous crops caused by Fusarium spp. was suppressed by Trichoderma spp. and with the growth of the treatment plant root system (Raats 2012). T. atrorviride can be used to control a large number of soil-borne fungi $F$. solani and Pythium spp. (Ngo et al. 2006). In the present study, the plant height was also increased in plants treated with $T$. atroviride, and this may be due to suppress the infection, encouragement of plant resistance, high nutrient uptake, and promotion of plant development. Present findings were in accordance with (Rinu et al. 2014) by applying T. gamsi against numerous plant pathogenic fungi including Fusarium oxysporum, F. solani, F. pallidoroseum, Alternaria alternate, Pythium afertile, and Phomopsis archeri.

\section{Conclusions}

The present results revealed that the T. atroviride isolated from healthy tomato rhizosphere soil can be used effectively to manage tomato wilt disease. The study showed antagonistic potentials of $T$. atroviride, as a biological control agent against $F$. oxysporum, in vitro and under greenhouse experiment. T. atroviride could limit disease incidence and severity by inhibition of $F$. oxysporum growth through many mechanisms such as mycoparasitism, and antifungal metabolite synthesis.

\section{Abbreviations \\ DI: Disease incidence; PDA: Potato dextrose agar; SEM: Scanner electron microscope; TSM: Trichoderma selective medium; P: Pathogen; F: Fungicide $\mathrm{T}$ : T. atroviride}

\section{Acknowledgements}

For Sadat City University and Al-Azhar University

\section{Authors' contributions}

NAM performed the experiments, analyzed and interpreted the data, and wrote the paper.

MAE performed some of the experiments, analyzed and interpreted the data. ATM conceived and designed the experiments, analyzed and interpreted the data, and wrote the paper. M A analyzed and interpreted some data, and wrote the paper. The authors have read and approved the manuscript.

\section{Funding}

This research did not receive any specific grant from funding agencies in the public, commercial, or not-for-profit sectors.

\section{Availability of data and materials}

All data generated or analyzed during this study are included in this published article.

\section{Declarations}

Ethics approval and consent to participate Not applicable

\section{Consent for publication}

Not applicable

\section{Competing interests}

The authors declare that they have no competing interests.

\section{Author details}

${ }^{1}$ Sustainable Development Department, Environmental Studies and Research Institute, University of Sadat City, Sadat City, Egypt. ${ }^{2}$ Botany and Microbiology Department, Faculty of Science, Al-Azhar University, Cairo, Egypt. ${ }^{3}$ Microbial Biotechnology Department, Genetic Engineering and Biotechnology Research Institute, University of Sadat City, Sadat City, Egypt.

Received: 11 March 2021 Accepted: 3 July 2021

Published online: 11 July 2021

\section{References}

Abo-Elyousr KAM, Mohamed HM (2009) Note biological control of fusarium wilt in tomato by plant growth-promoting yeasts and Rhizobacteria. Plant Patho J 25(2):199-204. https://doi.org/10.5423/PPJ.2009.25.2.199

Anjul R, Manvika S, Johri BN (2017) Fusarium oxysporum: genomics, diversity and plant-host interaction, (c) Springer Nature Singapore Pte Ltd. 159, https://doi. org/10.1007/978-981-10-4768-8_10.

Berghem LE, Pettersson LG (1974) The mechanism of enzymatic cellulose degradation. Isolation and some properties of a beta-glucosidase from Trichoderma viride. Eur J Biochem 46(2):295-305. https://doi.org/10.1111/ j.1432-1033.1974.tb03621.x

Booth C (1985) The genus Fusarium. Commonwealth Mycological Institute, Kew. Surrey, England, $237 \mathrm{pp}$.

Dennis C, Webster J (1971) Antagonistic properties of species group of Trichoderma II. Production of volatile antibiotics. Trans Brit Mycol Soc 57:6369

Dhingra OD, Sinclair JB (1985) Basic plant pathology methods. CRC Press, Inc, Boca Raton

El-Sobky MA, Fahmi Al, Eissa RA, El-Zanaty AM (2019) Genetic characterization of Trichoderma spp. isolated from different locations of Menoufia, Egypt and assessment of their antagonistic ability. J Microb Biochem Technol 11:1. https://doi.org/10.4172/1948-5948.1000409 
Fang DF, Xilin L, Xiaorong C, Wenwu Y, Yunlu H, Yi C, Jia C, Zhimin L, Litao G, Tuhong W, Xu J, Chunsheng G (2020) Fusarium Species and Fusarium oxysporum species complex genotypes associated with yam wilt in SouthCentral China. Front Microbiol 11:1964. https://doi.org/10.3389/fmicb.2020.01 964

Kubicek CP, Harman GE (2002). Trichoderma and Gliocladium (vol. I). Basic biology, taxonomy and genetics. pp. 14-24.

Mohamed BFF, Sallam NMA, Alamri SAM, Abo-Elyousr KAM, Mostafa YS, Mohamed H (2020) Approving the biocontrol method of potato wilt caused by Ralstonia solanacearum (Smith) using Enterobacter cloacae PS14 and Trichoderma asperellum T34. Egypt J Biol Pest Control 30(1):61. https://doi. org/10.1186/s41938-020-00262-9

Ngo BH, Vu DN, Tran DQ (2006) Analyze antagonist effects of Trichoderma spp. for controlling southern stem rot caused by Sclerotium rolfsii on peanut. Plant Protection 1:12-14

Nwankiti AO, Gwa VI (2018) Evaluation of antagonistic effect of Trichoderma Harzianum against Fusarium oxysporum causal agent of white Yam (Dioscorea rotundata Poire) Tuber Rot Trends Tech Sci Res 1(1): TTSR. MS. ID.555554.

Pandey KK, Vishwakarma SN (1998) Growth, sporulation and colony characters of Alternaria alternata on different vegetable-based media. J Mycol Plant Pathol (India) 28:346-347

Raats PAC (2012) Effect of Trichoderma species on damping-off disease incidence, some plant enzymes activity and nutritional status of bean plants. Int J Agriculture Environ 2:13-25

Ramezani H (2009) Efficacy of fungal and bacterial bioagents against Fusarium oxysporum f. sp. cicerion chickpea. Plant Protect J 1:108-113

Renu J (2018) A review of Fusarium oxysporum on its plant interaction and industrial use. J Med Plants Stud 6(3b):112-115

Rinu K, Sati P, Pandey A. Trichoderma gamsii (NFCCI 2177) (2014) a newly isolated endophytic, psychrotolerant, plant growth promoting, and antagonistic fungal strain. J Basic Microbiol. 2;54(5):408-17. https://doi.org/1 $0.1002 / j o b m .201200579$.

Saad AMA, Hashem M, Mostafa YS, Nafady NA, Abo-Elyousr KAM (2019) Biological control of root rot in lettuce caused by Exserohilum rostratum and Fusarium oxysporum via induction of the defense mechanism. Biological Control 128: 76-84

Sallam NMA, Eraky AMI, Sallam A (2019) Effect of Trichoderma spp. on Fusarium wilt disease of tomato. Mol Biol Rep 46(4):4463-4470. https://doi.org/10.1 007/s11033-019-04901-9

Shehata MM (2001). Studies on tomato root-rot disease and their control. M. Sc., thesis Fac. of Agriculture El-Azhar University, Cairo, Egypt.

Shrinkhala M, Bimala P, Chetana M, Suraj B (2019) In-vitro evaluation of biocontrol agents against soil borne plant pathogens. J Nepal Agricult Res Council 5:68-72

Tuite J (1996) Plant pathological methods. Fungi and Bacteria Burgess Pub. Co. Minneapolis, Minn. USA.293 pp.

\section{Publisher's Note}

Springer Nature remains neutral with regard to jurisdictional claims in published maps and institutional affiliations.

\section{Submit your manuscript to a SpringerOpen ${ }^{\circ}$ journal and benefit from:}

- Convenient online submission

- Rigorous peer review

- Open access: articles freely available online

- High visibility within the field

- Retaining the copyright to your article

Submit your next manuscript at $\boldsymbol{\nabla}$ springeropen.com 